\title{
Evidence of significant results showing staying active is advisable for non-Specific low back pain patients: a systematic review
}

\begin{abstract}
Clinical procedures encourage exercises and activities for Non-specific Low Back Pain (NSLBP). However, the relationship between the levels of physical exercise and their results is still unclear. Therefore, this review explains the relationships between the level of free living activity following Low Back Pain (LBP) and the levels of pain. It also describes impairment in patients with NSLBP. The paper used AMED, OVID, Biomed, CINAHL, Medline, Embase, Google scholar PubMed-National Library of Medicine, Proquest Directories, and manual reference lists searches to locate relevant literature. Only studies that examined statistical relationship between activities of free living Physical Activity (PA) in subjects with LBP and LBP outcome procedures were included in this review. Altogether, twelve studies, consisting of seven cohorts and five cross-sectional studies were included in this review. Out of the twelve studies, only one showed statistically significant relationship between increased leisure time activity and improved LBP outcomes. Another study reported reduced levels of sporting activity to be linked with higher levels of discomfort and disability. The rest $(n=10)$ demonstrated no connection between activity levels and pain. The studies also demonstrated that NSLBP patient's activity levels are neither connected with nor predictive of the pain levels. This paper recommends prospective research to thoroughly determine the relationships between PA, LBP and activity levels.
\end{abstract}

Volume I Issue $6-2017$

\author{
Qais Gasibat,' Hatem Mustafa Dermish,'2 \\ Reda Rajab alhmali, ${ }^{2}$ Isam Denna ${ }^{3}$ \\ 'Faculty of Medicine, University Sultan Zainal Abidin, Malaysia \\ ${ }^{2}$ Department of Physiotherapy, General Hospital of Miusrata, \\ Libya \\ ${ }^{3}$ Department of nutrition, University of Benghazi, Libya
}

Correspondence: Qais Gasibat, Faculty of Medicine, University Sultan Zainal Abidin, Malaysia, Tel 060104258488, 002189255।5056,Email drqaiss9@gmail.com

Received: September 13, 2017 | Published: October 13, 2017

Keywords: non-specific low back pain, exercises, bed rest, stay active

\section{Introduction}

Physical exercise (PA) is globally acknowledged as a key strategy in the treatment management of acute and chronic low back pain (CLBP). ${ }^{1-5}$ Among the main recommendations of LBP management include staying active, early and consistent treatment, and discouragement of bed snooze. ${ }^{6-9}$ Somehow, it is highly challenging to effectively manage LBP and prevent pain reoccurrence and chronicity. ${ }^{10,11}$ Thus, there has been increasing works on the creating of techniques in of averting the adverse impacts of CLBP. ${ }^{12}$ PA's prospective role in CLBP prevention has been recommended. ${ }^{13}$ As recently found, staying active appears to be a primary component of active self-management in those with CLBP. ${ }^{14}$ As a management technique for acute and chronic LBP populations, graded activity programmes have been conducted. ${ }^{15-18}$ However, within free living, the activity amounts have not been assessed. Thus, determining the romantic relationship between any activity switch and LBP recovery measures is impossible.

In general, the LBP patients' proposed effect of pain on activity levels hinges on LBP's deconditioning model ${ }^{19}$ which is backed by evidence of many changes in terms of: physical fitness ${ }^{20}$ physical working $^{21}$ neuromuscular adjustments ${ }^{22}$ psychological outcomes ${ }^{23}$ reductions in changes within the patterns ${ }^{16}$ and LBP patients' activity amounts. ${ }^{24}$ The proof for deconditioning due to LBP has been challenged. ${ }^{25}$ Further, some researches indicated no difference in any of the fitness levels ${ }^{20,26}$ or the levels of activity demonstrated by these patients as opposed to the healthy control group. ${ }^{27}$ Nonetheless, the notion of whether the activity levels of LBP patients are linked with LBP outcomes is not much understood. In relation to this, there appears a dose-response relationship between PA in the primary and supplementary prevention and management of many chronic diseases. ${ }^{28}$ However, the part of activity in LBP individuals is yet to be ascertained. For LBP patients, the level of activity will not seem to be a significant prognosis predictor. ${ }^{10,29}$ Albeit the existence of budding studies, no specific examination like a potential prognostic factor was included in them. Thus, this systematic assessment will primarily delve into the relationship among PA levels in LBP patients and applicable outcome measures which comprise measures of LBP linked disability and pain. This paper will also ascertain if certain activity amounts and/or types of actions have direct linkage with LBP outcome measures.

\section{Methods}

This paper comprises a systematic review of NSLBP observational research examining the relationships among PA levels and LBP outcome measures. Notably, in finding the predictive relationships, longitudinal analyses in a randomised control trial style are desirable ${ }^{30,31}$ but a cross-sectional design is also suitable for this exploratory relationships analysis between activity and LBP.

The fitting studies for this review were independently searched by three reviewers. For this purpose, a number of databases were used including AMED, Biomed, OVID, CINAHL, Embase, Medline, Google scholar PubMed National Library of Medicine as well as Proquest (1990 to January 2017). During the search process, the texts and keywords used include: activity level, activities of daily living, activity questionnaire, activity diary, energy expenditure, physical activities, disuse and LBP. The study search was limited to works published in English language. 


\section{Inclusion criteria}

This review generally comprises studies on LBP. However, some LBP related studies were not included. The excluded LBP studies include research which specifically assessed the workout therapy for LBP but did not address free living activity. The dimension of free living activity refers to a method of measuring activity performed daily such as activities of work, leisure and sports. ${ }^{32}$ Other excluded studies are those that only addressed activity restriction or discomfort with activity, which scored activities with which the patient find difficult as opposed to with their specified actual level or the PA type. Further, psychosocial elements such as fear avoidance, work satisfaction and reconnaissance of control were not regarded as LBP's key outcome measures.

\section{Data extraction}

Data extraction was performed by 3 reviewers independently and differences that occurred were solved via consensus through meeting with a third reviewer. Standard data extraction sheet was used in info extraction and tabulation. The included data are: research design, amount of participants, type of control group (if applicable), demographic characteristics (gender, age group and LBP type [acute, sub-acute and chronic]), received treatment (if applicable), PA measurement particulars, lifetime PA measurement, follow-up timing and duration, utilised end result measures which include methods and standard deviations, regret rates, as well as the statistical romantic relationship between PA and LBP outcome measure.

\section{Results}

\section{Study selection}

A total of 78 studies assessed PA in LBP population, but 66 of these studies were excluded. The reasons for exclusion include: post-lumbar surgery, inexistence of direct comparison of PA with an LBP outcome solution, measurement of only night-time activity, retrospective PA assessment, low back pain combined with other pains, and unclear free living PA assessment method. ${ }^{33}$

\section{Study characteristics}

A total of 12 articles measured PA within adult NSLBP population and the relationship with substantial LBP outcome measure was measured. Here, there are seven cohort researches (refer Table 1) and five cross-sectional studies (refer Table 2). A number of studies employed randomised controlled trials in assessing the effectiveness of many future interventions. ${ }^{4,33-35}$ Still, these works also looked into the relationship between activity and LBP within a longitudinal cohort design in the assessment of the relationship of activity towards the outcome measure.

Table I Characteristics and results of cohort studies

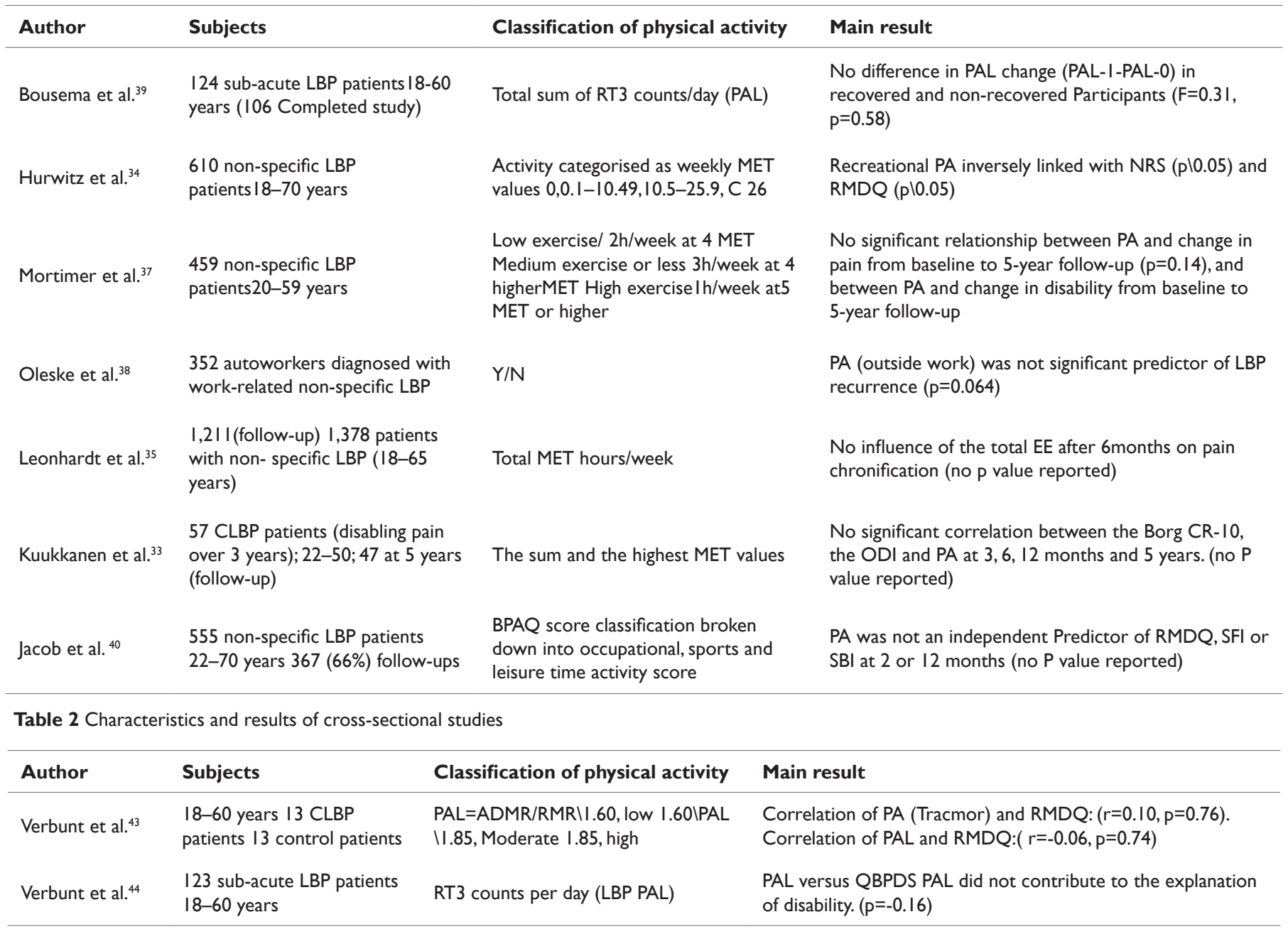


Table Continued....

\begin{tabular}{|c|c|c|c|}
\hline Author & Subjects & Classification of physical activity & Main result \\
\hline Cunha et al. ${ }^{45}$ & $\begin{array}{l}5 \text { I non-specific LBP patients } \\
26-65 \text { years of age }\end{array}$ & Scale rating $(0-8)$ & Correlation of PA with RMDQ ( $r=-0.04)$ \\
\hline Johansson et al. ${ }^{42}$ & $\begin{array}{l}72 \text { participants } 18-65 \\
\text { years) At least } 4 \text { weeks of } \\
\text { LBP }\end{array}$ & $\begin{array}{l}\text { Scale: } 18 \text { items on activities } \\
\text { performance }(0=\text { never to } 6=\text { very } \\
\text { often })\end{array}$ & $\begin{array}{l}\text { No significant relationship between PA and RMDQ.Low } \\
\text { negative correlation of RM-SW with general activity }(r=0.27 \text {, } \\
\text { pl0.05) }\end{array}$ \\
\hline Jacob et al. ${ }^{4 l}$ & $\begin{array}{l}555 \text { non-specific LBP } \\
\text { patients } 22-70 \text { years }\end{array}$ & $\begin{array}{l}\text { BPAQ score classification into N/A } \\
\text { occupational, sports and leisure time } \\
\text { activity score }\end{array}$ & $\begin{array}{l}\text { Significan relationship between } \mathrm{SAI} \text { and }(\mathrm{Beta}, 95 \% \mathrm{Cl}) \mathrm{RMDQ} \\
(-0.09,-0.1 \text { to }-0.02) \mathrm{SFI}(-0.08,-0.14 \text { to }-0.02) \mathrm{SBI}(-0.06 \\
-0.1 \text { to }-0.005)\end{array}$ \\
\hline
\end{tabular}

\section{Cohort studies}

In this review, one article reported a significant relationship between activity and LBP. Here, recreational activity which comprises amusement activities and combined sports appeared to be negatively linked with discomfort as well as disability at 1.5 years. ${ }^{34}$ The likelihoods of obtaining a clinically meaningful impairment were $30 \%$ less amongst participants in the upper two quartiles of the PA circulation as opposed to among sedentary individuals. The rest of the studies concluded no significant relationship between levels of activity and LBP impairment, pain or healthcare usage.

\section{Types of participants}

Almost all researches selected partakers within the working age population, that is, those aged between 18 and 65 years, whom were diagnosed with NSLBP with different symptom duration. ${ }^{35-38}$ PA within exclusively sub-acute was explored in two studies. ${ }^{32} \mathrm{PA}$ was also examined in CLBP populations. ${ }^{33}$ In general, the disability and discomfort in terms of levels at entry into the research were moderate. ${ }^{33,34,37-40}$ Conversely, more recent research concluded mixed levels of disability ${ }^{35}$ where most individuals from three organizations had a low disability ranking.

\section{Activity measurement}

The studies all used a range of PA measures including the Tracmor accelerometer, which involves counts/ min and DLW (PAL $=\mathrm{ADMR} /$ RMR), RT3 tri axle accelerometer activity $\log$ BPAQ, self-reported PA rating with a scale range of $0-8$, the general activity scale comprising self-reported questionnaire and BPAQ that is self-administered (here, only one employed an objective measure of $\mathrm{PA}^{39}$ whereas the rest examined PA with numerous types of recall questionnaires). Meanwhile, four studies utilised self-report questionnaires that classed numerous activities into metabolic equivalent of task (MET) energy levels, ${ }^{33-35,37}$ whereas one study employed a questionnaire that necessitates the participants' response of 'yes/no' on their participation of exercise or activity outside work. ${ }^{38}$ Only Jacob et al. ${ }^{40}$ used a validated LBP recall instrument ${ }^{41}$ at 1 -year follow-up in an observational research ${ }^{36}$ while other PA recall questionnaires had not been tested in terms of reliability and validity in the context of LBP population.

Three studies employed the repeated measures design in examining the partnership between activity and LBP. Here, in studying the amount of leisure time (in hours) spent per week on strolling and on light, moderate and intense physical activity ${ }^{34}$ concluded a significant relationship among PA and LBP in at all four dimension points. Another study that also employed PA measures reported that women in the 'medium' exercise group reported the highest (66\%) onset periods of acute/sub-acute NSLBP during the past 5 years, as opposed to those in the low and high workout groups for the same time duration. ${ }^{37}$ However, the similar study by Jacob et $a .^{40}$ concluded no predictive relationship between PA namely work, leisure and occupational score (using only one baseline measurement) and discomfort or disability, within the duration of one year.

\section{Follow-up characteristics}

The duration of 1 year was the minimum follow-up period. Meanwhile, the amount and scale of follow-up intervals are in the range between two measurements (at primary and at 1 year $^{39}$ ) and five individual measurements in the period of 5 years. ${ }^{33}$ For the studies reviewed, the follow-up saw loss of individuals ranging from $42 \%$ for the duration of more than 5 years $^{37}$ to $10 \%$ for the duration of above 18 months. ${ }^{34}$ However, there were no report of follow-up loss in two studies, namely, ${ }^{34,38}$ while one did not take into account the possible impacts of follow-up loss. ${ }^{33}$

\section{Confounding factors included in the relationship between and activity and LBP}

Most potential works involved some prospective confounders within the multivariate analyses except for two that did not assess and make adjustment for such elements. ${ }^{33,37}$ Meanwhile, one study ${ }^{34}$ attempted to discover significant relationship between activity and LBP in multivariate analyses. Here, a larger number and range of prospective confounders were included in terms of behavioural, psychosocial alongside other individual characteristics.

\section{Cross-sectional studies}

Of the five cross-sectional studies, only one concluded a significant relationship between PA and measures of $\mathrm{LBP}^{36}$ noting low sports activity index (SAI) scores which led to higher scores for nearly all measures of LBP.

\section{Types of participants}

All five cross-sectional studies reviewed used patients from the working age group, that is, the age range of $18-65$, while their LBP ranged from sub-acute ${ }^{42,43}$ to chronic ${ }^{44}$ However, two studies namely Jacobs et al. ${ }^{36}$ and Cunha et al. ${ }^{45}$ included patients with a range of LBP durations as well.

Quality wise, the studies significantly differ, and no study was particularly aimed at investigating the relationships between activity and LBP. The number of participants employed by the studies ranged from 13 to 555, and most employed small numbers of participants which may be linked to lack of observed relationships. Jacob et al..$^{36}$ was an exception, where a relationship between PA and low back pain outcomes was reported $(\mathrm{n}=550)$. 
One study ${ }^{44}$ selected two types of participants: those with and those without LBP; their activity levels were then compared, while other studies were focusing on populations with LBP only. The studies all employed validated LBP disability measures and some studies also included measures of pain, depression and fear avoidance.

\section{Activity measurement}

Objective steps of PA were used in two studies ${ }^{28,46}$ while three works utilised the numerous kinds of PA recall questionnaires. Verbunt ainsiqu et al. ${ }^{44}$ employed the doubly labelled drinking water $(\mathrm{DLW})^{46}$ while the Tracmor accelerometer ${ }^{47}$ is utilised in the sub-classification of activity levels into low, moderate and high. Furthermore, RT3 accelerometer alongside a task log and the Beacke physical exercise questionnaire (BPAQ) were employed by a study ${ }^{43}$ that investigated the contribution of activity to the sub-acute LBP population. Meanwhile, self-reported activity scales were used in two studies ${ }^{45,42}$ for the assessment of free living activities. Somehow, none of these self-reporting instruments were validated for the measurement of activity of LBP masses. Also, there were little data in within the population of healthy individuals for comparative solution. The work by Jacob et al. ${ }^{36}$ used the BPAQ ${ }^{48}$ as a validated instrument of PA in sub-classifying the work-related, sports and leisure activities of partakers.

\section{Discussion}

Little evidence has been found on the romantic relationship between free living PA and measures of impairment, pain or health utilization among NSLBP sufferers. In fact, only one cohort study documented a statistically significant relationship among activity and disability ${ }^{34}$ by which, decreased recreational activity levels were found to negatively linked with pain ( $\backslash \backslash 0.05)$ and LBP-related disability (p $\backslash 0.05)$. Further, one cross-sectional study ${ }^{36}$ mentioned lower amounts of self-reported sporting activity to be linked with greater discomfort and disability levels. The rest (10 studies) reported relationship between free living PA and LBP outcome measures, irrespective of whether the study was cross-sectional or longitudinal. Such outcomes point to the role played by activity among LBP patients. Since the cross-sectional design does not ascertain cause/effect associations between two factors ${ }^{31}$ prospective relationships between activity and outcome measures of LBP were mainly from the outcomes from prospective cohort studies. These observational studies are of value to health studies especially in the evaluation of prognostic or aetiological factors ${ }^{49,50}$ The outcomes currently obtained offer moderate proof $(\text { level II })^{49}$ that activity, or change in activity, among NSLBP sufferers is not predictive of or linked to LBP outcomes.

The standard of the observational studies was mixed, and there were numerous research design issues influencing the validity of the findings. A variety of PA measures had been used, most commonly recall forms, with the majority either untested or non-validated within LBP populations. Activity measures utilized by Leonhardt et al. ${ }^{35}$ allowed for specific comparisons to non-LBP populations ${ }^{51}$ while the $\mathrm{BPAQ}^{40}$ lets comparison to both LBP and non-LBP populations. ${ }^{41}$ The generic MET-based questionnaires have provided even more general comparison to activity levels in other populations even though different methods of calculation expose potential for bias or confounding. Validation and between research comparison of activity measurement equipment is important as it allows immediate and accurate comparisons of PA measurement and the analysis of change in activity.
Mixed standards were used by the observational studies. Also, many issues pertaining to research design were impacting the findings in terms of validity. Numerous measures of PA had been employed and most of them were in the form of recall. Further, most instruments used were either untested or non-validated in the context of LBP populations. Activity measures that Leonhardt et al. ${ }^{33}$ had used enabled certain comparisons to non-LBP populations. ${ }^{51}$ Meanwhile, the use of $\mathrm{BPAQ}^{40}$ allows researcher to compare both LBP and non-LBP populations. ${ }^{41}$ The utilisation of generic MET-based questionnaires allows researcher with even more general comparison to activity levels in other populations although different computation methods carry the risk of bias or confounding. It is also important to make validation and comparison between activity measurement equipment in order to produce instantaneous and precise comparisons of PA measurement and the analysis of change in activity.

It is possible that the usage of PA recall questionnaires impacted the obtained outcomes in terms of reliability and validity. The capacity in accurately assessing and determining change of activity over time differs between objective and the instruments of activity recall. ${ }^{51,52}$ It should be noted that the use self-report measures in some studies did not state to the participants that activities should only be documented following the recent LBP occurrence. ${ }^{33-35,38}$ Thus, it is possible that participants may also have reported activity levels that occurred before the LBP onset. If these are different in comparison to activity levels with LBP, the prospective effect of PA on recovery may be clouded.

Prospective confounders to the relationship between activity and disability were also discovered. ${ }^{11}$ Also, there appear factors that mediate between PA and disability. ${ }^{53,54}$ Several behavioural and psychosocial variables appear to be related to the multivariate models. Somehow, a research that comprehensively explores the potential mediating impacts of these variables on the linkage between activity and the LBP outcome is yet to be conducted. It is possible that the non-associations are impacted by other behavioural or psychosocial factors such as fear avoidance. ${ }^{55}$ Therefore, these factors may confound or moderate the relationship between PA and LBP.

\section{The role of activity and exercise in LBP}

It appears that staying active as addition to physiotherapy treatment generates desirable results to those with acute and those with persistent LBP. ${ }^{14,56}$ Somehow, there have been no studies that specifically measure PA in the population of LBP sufferers. ${ }^{14}$ The roles of PA in LBP problem has been studied ${ }^{57-60}$ but no definitive conclusions have been drawn. A short recall set of questions was used in a recent study to evaluate the retrospective romantic relationship between activity and LBP's stage prevalence. Here, a U-shaped marriage in high and also in low amounts of activity causes the likelihood of a retrospective report of LBP chronicity to increase especially among women. ${ }^{3,4,39}$ One study (longitudinal) specifically classed activities into low, moderate and high amounts at baseline and employed the self-report measures to investigate romance with LBP outcomes. ${ }^{37}$ At five years, no significant relationship was found between the documented activity levels in baseline and change in discomfort and disability. There was no study that particularly determined if repair of a judicious activity level during LBP episode (compared low or large activity levels) is linked to the outcomes. More longitudinal studies should be carried out on prospective U-shaped effects on insufficient or excessive activity amounts. In LBP management, exercise generally leads to positive outcomes. ${ }^{61-63}$ Still, this paper pioneers the assessment 
of the relationship between the activity levels of LBP patients with specified degree of disability and pain, and recovery. As activity in LBP management is important, this review demonstrates the dearth of works in this domain. There is also insufficient evidence of a positive role of activity in this population (LBP sufferers). ${ }^{64-68}$

\section{Conclusion}

This paper systematically reviewed the relationship between free living physical activity among NSLBP sufferers and outcomes, recovery and reoccurrence. The outcomes indicate no support toward the relationship between activity and NSLBP outcome measures. Somehow, detrimental effects from involving in higher levels of activity among LBP patients were also not found. As increase in activity is found to benefit one's health, LBP patients are advised to start, maintain and increase (where applicable) their physical activities as part of their daily routine. The outcomes also call for the need for further works for the evaluation and clarification of PA part for NSLBP patients with respect to the outcome and prognosis.

\section{Acknowledgements}

We would like to express our gratitude to the Libyan Embassy in Malaysia for its support during the course of this paper. We also thank our colleagues who provided insight and expertise that greatly helped in the process of writing this manuscript.

\section{Conflict of interest}

Authors declare there is no conflict of interest in composing this manuscript.

\section{References}

1. Arnau JM, Vallano A, Lopez A, et al. A critical review of guidelines for low back pain treatment. Eur Spine J. 2006;15(5):543-553.

2. Tulder M, Becker A, Bekkering T, et al. Chapter 3: European guidelines for the management of acute nonspecific low back pain in primary care. Eur Spine J. 2006;15(2):S169-191

3. Gasibat Q, Simbak N, Aniza AA, et al. A comparative efficacy between strength and Stabilisation training programmes in the Improvement of trunk and hip muscles Activations of healthy females subject: An implication for the rehabilitation Practitioners. International Journal of Life \& Pharma Research. 2017;7(4):30-38.

4. Gasibat Q, Simbak N, Aniza AA, et al. Effect of the stabilization training programme in the improvement of trunk and hip muscles activations among healthy females subject: An implication for the rehabilitation experts. Journal of Physical Education and Sport. 2017;17(3):948-954.

5. Qais G, Nordin BS, Saad ELB, et al. Measuring the Relationship between Obesity and Low Back Pain: A Review Article. American Journal of Medical Sciences and Medicine. 2017;52(2):35-39.

6. Bekkering GE, Hendriks HJM, Koes BW, et al. Dutch physiotherapy guidelines for low back pain. Physiotherapy. 2003;89(2):82-96.

7. Koes BW, van Tulder MW, Ostelo R, et al. Clinical guidelines for the management of low back pain in primary care: an international comparison. Spine. 2001;26(22):2504-2513.

8. Gasibat Q, Simbak NB. Moderation of Back pain by Rehabilitation Exercises; Multifidus Muscle 'Perspective. IOSR Journal of Sports and Physical Education. 2017;4(1):14-18.

9. Gasibat Q, Simbak NB. Modified rehabilitation exercises to strengthen the gluteal muscles with a significant improvement in the lower back pain. International Journal of Yoga, Physiotherapy and Physical Education. 2017;2(1):20-24.
10. Kent PM, Keating JL. Can we predict poor recovery from recentonset nonspecific low back pain? A systematic review. Man Ther. 2008;13(1):12-28

11. Refshauge KM, Maher CG. Low back pain investigations and prognosis: a review. Br J Sports Med. 2006;40(6):494-498.

12. Majid K, Truumees E. Epidemiology and natural history of low back pain. Semin Spine Surg. 2008;20(2):87-92.

13. Karmisholt K, Gotzsche PC. Physical activity for secondary prevention of disease. Systematic reviews of randomised clinical trials. Dan Med Bull. 2005;52(2):90-94.

14. Liddle SD, Gracey JH, Baxter GD. Advice for the management of low back pain: a systematic review of randomised controlled trials. Man Ther 2007;12(4):310-327.

15. Hlobil H, Staal JB, Twisk J, et al. The effects of a graded activity intervention for low back pain in occupational health on sick leave, functional status and pain: 12-month results of a randomized controlled trial. J Occup Rehabil. 2005;15(4):569-580.

16. Weering MGH, Vollenbroek HMMR, Tonis TM, et al. Daily physica activities in chronic lower back pain patients assessed with accelerometry Eur J Pain. 2008;13(6):649-654.

17. Gasibat Q, Simbak NB, Aziz AA, et al. Stretching Exercises to Prevent Work-related Musculoskeletal Disorders-A Review Article. American Journal of Sports Science and Medicine. 2017;5(2):27-37.

18. Gasibat Q, Suwehli W. Determining the Benefits of Massage Mechanisms: A Review of Literature. Rehabilitation Sciences. 2017;2(3):58-67.

19. Wittink H, Hoskins Michel T, Wagner A, et al. Deconditioning in patients with chronic low back pain: fact or fiction?. Spine. 2000;25(17):22212228 .

20. Smeets RJE, Wittink H, Hidding A, et al. Do patients with chronic low back pain have a lower level of aerobic fitness than healthy controls? Are pain, disability, fear of injury, working status, or level of leisure time activity associated with the difference in aerobic fitness level? Spine. 2006;31(1):90-98

21. Di Iorio A, Abate M, Guralnik JM, et al. From chronic low back pain to disability, a multifactorial mediated pathway: the InCHIANTI study. Spine. 2007;32(26):E809-E815.

22. Hammill RR, Beazell JR, Hart JM. Neuromuscular consequences of low back pain and core dysfunction. Clin Sports Med. 2008;27(3):449-462.

23. Storheim K, Ivar Brox J, Holm I, et al. Predictors of return to work in patients sick listed for sub-acute low back pain: a 12-month follow-up study. J Rehabil Med. 2005;37(6):365-371.

24. Berg ERJ, Schasfoort FC, de Vos LA, et al. Impact of chronic pain on everyday physical activity. Eur J Pain. 2007;11(5):587-593.

25. Smeets RJEM, Wittink $\mathrm{H}$. The deconditioning paradigm for chronic low back pain unmasked?. Pain. 2007;130(3):201-202.

26. Rasmussen BE, Lundqvist L, Nilsson WL, et al. Aerobic fitness in patients at work despite recurrent low back pain: a cross-sectional study with healthy age- and gendermatched controls. $J$ Rehabil Med. 2008;40(5):359-365.

27. Smeets RJ, van Geel KD, Verbunt JA Is the fear avoidance model associated with the reduced level of aerobic fitness in patients with chronic low back pain? Arch Phys Med Rehabil. 2009;90(1):109-117.

28. Warburton DER, Nicol CW, Bredin SSD. Health benefits of physical activity: the evidence. Can Med Assoc J. 2006;174(6):801-809.

29. Steenstra IA, Verbeek JH, Heymans MW, et al. Prognostic factors for duration of sick leave in patients sick listed 123 with acute low back pain: a systematic review of the literature. Occup Environ Med $2005 ; 62(12): 851-860$. 
30. Altman DG, Schulz KF, Moher D, et al. The revised CONSORT statement for reporting randomised trials: explanation and elaboration Ann Intern Med. 2001;134(8):663-695.

31. Cole DA, Maxwell SE. Testing mediational models with longitudinal data: questions and tips in the use of structural equation modeling. $J$ Abnorm Psychol. 2003;112(4):558-577.

32. Bouchard C, Blair SN, Haskell WL. Physical activity and health. 2nd ed. USA: Human Kinetics; 2007.

33. Kuukkanen T, Malkia E, Kautiainen H, et al. Effectiveness of a home exercise programme in low back pain: a randomized five-year follow-up study. Physiother Res Int. 2007;12(4):213-224.

34. Hurwitz EL, Morgenstern H, Chiao C. Effects of recreational physical activity and back exercises on low back pain and psychological distress: findings from the UCLA Low Back Pain Study. Am J Public Health 2005;95(10):817-1824.

35. Leonhardt C, Keller S, Chenot JF, et al. TTM-based motivational counselling does not increase physical activity of low back pain patients in a primary care setting - a cluster-randomized controlled trial. Patient Educ Couns. 2008;70(1):50-60.

36. Jacob T, Baras M, Zeev A, et al. Physical activities and low back pain: a community-based study. Med Sci Sports Exerc. 2004;36(1):9-15.

37. Mortimer M, Pernold G, Wiktorin C. Low back pain in a general population. Natural course and influence of physical exercise-a 5-year follow-up of the Musculoskeletal Intervention Center-Norrtalje Study. Spine. 2006;31(26):3045-3051.

38. Oleske DM, Lavender SA, Andersson GBJ, et al. Risk factors for recurrent episodes of work-related low back disorders in an industrial population. Spine. 2006;31(7):789-798.

39. Bousema EJ, Verbunt JA, Seelen HAM, et al. Disuse and physical deconditioning in the first year after the onset of back pain. Pain. 2007;130(3):279-286.

40. Jacob T, Baras M, Zeev A, et al. A longitudinal, community-based study of low back pain outcomes. Spine. 2004;29(16):1810-1817.

41. Jacob T, Baras M, Epstein L. Low back pain: reliability of a set of pain measurement tools. Arch Phys Med Rehabil. 2001;82(6):735-742.

42. Johansson E, Lindberg P. Subacute and chronic low back pain. Reliability and validity of a Swedish version of the roland morris disability questionnaire. J Rehabil Med. 1998;30(3):139-140.

43. Verbunt JA, Sieben JM, Seelen HA, et al. Decline in physical activity, disability and pain-related fear in sub-acute low back pain. Eur J Pain. 2005;9(4):417-425.

44. Verbunt JA, Westerterp KR, Seelen HA, et al. Physical activity in daily life in patients with chronic low back pain. Arch Phys Med Rehabil. 2001;82(6):726-730.

45. Cunha IT, Simmonds MJ, Protas EJ, et al. Back pain, physical function, and estimates of aerobic capacity: what are the relationships among methods and measures? Am J Phys Med Rehabil. 2002;81(12):913-920.

46. Ainslie P, Reilly T, Westerterp K. Estimating human energy expenditure: a review of techniques with particular reference to doubly labelled water. Sports Med. 2003;33(9):683-698.

47. Plasqui G, Westerterp KR. Physical activity assessment with accelerometers: an evaluation against doubly labeled water. Obesity. 2007; 15(10):2371-2379.

48. Pols MA, Peeters PHM, Ocke MC, et al. Validity and repeatability of a modified Baecke questionnaire on physical activity. Int J Epidemiol. 1995;24(2):381-388.
49. Hoppe DJ, Schemitsch EH, Morshed S, et al. Hierarchy of evidence: where observational studies fit in and why we need them. $J$ Bone Joint Surg Am. 2009;91(Suppl 3):2-9.

50. Merlin T, Weston A, Tooher R. Extending an evidence hierarchy to include topics other than treatment: revising the Australian 'levels of evidence'. BMC Med Res Methodol. 2009;11(9):34.

51. Frey I, Berg A, Grathwohl DK, et al. Freiburger questionnaire on physical activity - design, validation and application. Soz Praventivmed. 1999;44(2):55-64.

52. Bassett DR, Cureton AL, Ainsworth BE. Measurement of daily walking distance-questionnaire versus pedometer. Med Sci Sports Exerc. 2000;32(5):1018-1023.

53. Motl RW, McAuley E, Snook EM, et al. Physical activity and quality of life in multiple sclerosis: Intermediary roles of disability, fatigue, mood, pain, self-efficacy and social support. Psychol Health Med. 2009;14(1):111-124.

54. Perruccio AV, Power JD, Badley EM. Arthritis onset and worsening selfrated health: a longitudinal evaluation of the role of pain and activity limitations. Arthritis Care Res. 2005;53(4):571-577.

55. Basler HD, Luckmann J, Wolf U, et al. Fear-avoidance beliefs, physical activity, and disability in elderly individuals with chronic low back pain and healthy controls. Clin J Pain. 2008;24(7):604-610.

56. Qais G, Wurida S, Abulgasim RB, et al. "The Effect of an Enhanced Rehabilitation Exercise Treatment of Non-Specific Low Back Pain- A suggestion for Rehabilitation Specialists." American Journal of Medicine Studies. 2017;5(1):25-35.

57. Hartvigsen J, Bakketeig LS, Leboeuf-Yde C, et al. The association between physical workload and low back pain clouded by the "healthy worker" effect: population-based cross-sectional and 5-year prospective questionnaire study. Spine. 2001;26(16):1788-1792.

58. Hartvigsen J, Frederiksen H, Christensen K. Physical and mental function and incident low back pain in seniors: a population-based twoyear prospective study of 1387 Danish Twins aged 70 to 100 years. Spine. 2006;31(14):1628-1632.

59. Levangie PK. Association of low back pain with selfreported risk factors among patients seeking physical therapy services. Phys Ther. 1999;79:757-766.

60. Smith MD, Russell A, Hodges PW. Disorders of breathing and continence have a stronger association with back pain than obesity and physical activity. Aust J Physiother. 2006;52(1):11-16.

61. Hayden JA, van Tulder MW, Tomlinson G. Systematic review: strategies for using exercise therapy to improve outcomes in chronic low back pain. Ann Intern Med. 2005;142(9):776-785.

62. Tulder M, Malmivaara A, Esmail R, et al. Exercise therapy for low back pain: a systematic review within the framework of the Cochrane Collaboration Back Review Group. Spine. 2000;25(21):2784-2796.

63. Wessels T, Sigl T, Ewert T, et al. What predicts outcome in non-operative treatments of chronic low back pain? A systematic review. Eur Spine J. 2006;15(11):1633-1644.

64. Downs SH, Black N. The feasibility of creating a checklist for the assessment of the methodological quality both of randomised and nonrandomised studies of health care interventions. J Epidemiol Community Health. 1998;52(6):377-384.

65. Heneweer H, Vanhees L, Picavet HSJ. Physical activity and low back pain: a U-shaped relation? Pain. 2009;143(1-2):21-25.

66. Huijnen IPJ, Verbunt JA, Roelofs J, et al. The disabling role of fluctuations in physical activity in patients with chronic low back pain. Eur J Pain 2009;13(10):1076-1079. 
67. Kamper SJ, Rebbeck TJ, Maher CG, et al. Course and prognostic factors of whiplash: a systematic review and meta-analysis. Pain. 2008;138(3):617-629.
68. Steenstra IA, Anema JR, Bongers PM, et al. The effectiveness of graded activity for low back pain in occupational healthcare. Occup Environ Med. 2006;63(11):718-725. 